\title{
Community philanthropy as practice: A case study of Thousand Currents
}

\author{
Fahad Ahmad ${ }^{1}(1) \cdot$ Ashlesha Khadse $^{2}(\mathbb{0}$
}

Received: 30 March 2021 / Accepted: 16 December 2021 / Published online: 11 January 2022

(c) The Author(s), under exclusive licence to Springer Nature Switzerland AG 2021, corrected publication 2022

\begin{abstract}
As philanthropy has emerged to play a prominent role in supporting community well-being efforts, important critiques have been raised about the undemocratic nature of philanthropy that appears to privilege private interests over community needs. In response to these concerns, Community Philanthropy (CP) has emerged as a philanthropic model that prioritizes community asset-building, agency, and trust in order to "shift power" to beneficiary communities (Hodgson \& Pond (2018). How community philanthropy shifts power. Grantcraft. Retrieved August 14, 2021, from https://grantcraft.org/content/guides/how-community-philanthropy-shifts-power). Despite its promise, questions remain about how $\mathrm{CP}$ can practically achieve the goals of sharing power, building trust, and showing solidarity toward community self-determination for well-being. To address these gaps, we examine the case of Thousand Currents, a public foundation that has pioneered a CP inspired grantmaking model. Thousand Currents provides long-term unrestricted grants to grassroots partners (grantees), learns about partner concerns, acts upon partner feedback, and is self-reflexive about its positional power as a funder. The foundation achieves its grantmaking objectives by taking deliberate fundraising and staffing decisions. Our case study showcases how other foundations can take steps towards actualizing CP.
\end{abstract}

Keywords Community philanthropy $\cdot$ Community well-being $\cdot$ Grassroots organizations $\cdot$ Social justice $\cdot$ Power

Fahad Ahmad

fs.ahmad@utoronto.ca

Ashlesha Khadse

ashlesha@ thousandcurrents.org

1 Centre for Criminology \& Sociolegal Studies, University of Toronto, Toronto, ON, Canada

2 Regional Director Asia and the Pacific, Thousand Currents, Oakland, CA, USA 


\section{Introduction}

Throughout the twentieth century, and specially with scaling back of government services under neoliberalism, philanthropic foundations have emerged to play a prominent role in supporting community well-being efforts (Eikenberry, 2006; Evans et al., 2005; Phillips, S.D. \& Jung 2016; Toepler, 2018). Private and community foundations have provided financial support and advocated for public policy changes to bolster economic growth, health and human services, education initiatives, arts and culture, and small businesses within various communities in the U.S. and internationally (Anheier \& Daly, 2006; Giloth, 2019; Harrow \& Jung, 2016; Johnson, P.D., 2018; OECD, 2019). As philanthropy has expanded its investments in communities, critiques of philanthropy have also sharpened. Political theorists have suggested that big philanthropy is fundamentally a topdown undemocratic exercise, yet has an outsized influence on public policy (Reich, 2018). This concern has only exacerbated with the very wealthy increasingly directing philanthropic efforts (Collins \& Flannery, 2020). Big philanthropy is thought to advance the private interests of philanthropists without challenging the economic and social structures that result in the need for philanthropy in the first place (Karl \& Katz, 1987; Roelofs, 2015). In practice, philanthropic funding has largely gone to initiatives that mirror the experiences of donors who control philanthropic institutions, and only minimally benefits systemic change (Schlegel, 2016). The structure of institutional philanthropy keeps intact the power that philanthropic institutions hold over grantees; there are numerous accounts of grant recipients amending priorities to satisfy foundation preferences (Barman, 2008; Kohl-Arenas, 2015; Ostrander, 2007). Important interventions have highlighted that the financial and social power of philanthropy is based on a history of colonialism, imperialism, and slavery (Villanueva, 2018). Ruth Wilson Gilmore (2016) remarks that "foundations are repositories of twice stolen wealth," which is accumulated based on exploitation but still sheltered from taxes. Finally, U.S. philanthropy is a white-dominated sector, particularly in decision-making positions, and funding for initiatives that benefit communities of color remains minimal (Cohen, 2014; Dorsey et al., 2020). Following these critiques, philanthropy is being asked to democratize, recognize community knowledge and assets, and prioritize social, economic, and racial justice (Hodgson \& Pond, 2018; Hossein, 2020; Reich, 2018; Suárez, 2012; Villanueva, 2018). In response, Community Philanthropy (CP) seeks to disrupt mainstream philanthropy by shifting power into the hands of communities and privileging community self-determination (Hodgson \& Pond, 2018). Based on the case study of a mid-sized U.S. public foundation - Thousand Currents - our intervention explicates how philanthropic institutions can adopt the principles and practices of CP.

The literature on CP evolved from a focus on community foundations that pool funds for investments in "place-based" communities (Harrow et al., 2016). More recently, however, international development practitioners have used CP to refer to a range of philanthropic efforts which privilege community-asset building, leadership and agency of communities, and trust-building (Hodgson \& Pond, 
2018; Layton, 2016). The aspirations of CP overlap with that of community wellbeing, where communities work to improve social, economic, environmental, and other conditions facing them based on their "needs and desires" (Lee et al., 2015, p. 2; Wiseman \& Brasher, 2008). Despite the CP literature highlighting optimistic cases in different national contexts (Kilmurray, 2015; Knight \& Milner, 2013; Wilkinson-Maposa, 2017), "limited guidance" exists for funders wanting to pursue CP (Doan, 2019, p. 3). For example, questions remain regarding what it means to "shift power," or how CP can engender trust-building under the structural constraints of a funder-grantee relationship, or the ways foundations can support community self-determination. Examining the extent to which Thousand Currents' philanthropic model reflects CP-related funder practices allows us to contribute to a deeper understanding of how foundations can adopt the principles and practices of community philanthropy.

Thousand Currents is a social justice funder that supports grassroots organizations and social movements working on food sovereignty, climate justice, and alternative economies in the Latin America, Africa, and Asia and the Pacific (Thousand Currents, n.d.-a). The foundation represents a paradigmatic case of CP as its grantmaking model privileges trust-based philanthropy and cedes agency to grassroots partners (grantees) by providing unrestricted grants. Thousand Currents expressly acknowledges its power and privilege as a funder and promotes trust-based grantmaking. In our analysis, we pay attention to how Thousand Currents confronts its positional power, builds mutual trust and accountability, and shows up in solidarity with self-determination efforts of its grassroots partners. Data for the analysis are drawn from organizational document review and interviews with ten participants - three from Thousand Currents' grassroots partners, two from foundations that support Thousand Currents, two board members, and three staff.

We find that Thousand Currents follows several principles and practices of community philanthropy such as adopting the orientation of "funder as learner," paying attention to values alignment with partners, investing in trust-building and mutual understanding, and committing to (downward) accountability towards partners. Feedback from partners is taken seriously as it has shaped the organizational strategy and resulted in new programming. Thousand Currents supports community self-determination by making flexible, long-term grants and by providing tangible non-financial support to its partners. Additionally, the foundation centers the views and voices of its partners and leverages its position to influence other funders to adopt justice-oriented, trust-based grantmaking. Operationally, adopting these practices has been backed by a series of deliberate decisions. Thousand Currents selects funders who are values-aligned and hires staff and board members who have lived experience and political education in the regions where partners are based. Ultimately, the foundation's grantmaking model recognizes the interconnectedness of global philanthropy with community well-being, offering a useful model for other foundations.

The rest of this article is organized as follows. We begin with a review of the $\mathrm{CP}$ literature. Based on this, we specify a model for CP-related funder practices that is used to examine the philanthropic model of Thousand Currents. Next, we elaborate our research methodology. Following that, we present our data analysis 
and discussion. We conclude the article with a reflection on what aspects of CP the Thousand Currents case foregrounds, underlining implications for other foundations.

\section{Assessing the Theory and Practice of Community Philanthropy}

Philanthropy is commonly understood as "the use of private resources - treasure, time and talent - for public purposes" (Phillips, S. D. \& Jung, 2016, p. 7). Inspired by Andrew Carnegie's proposition in The Gospel of Wealth, institutional philanthropy in the U.S. largely relies on the "charity" of the wealthy who use their economic and social stature to solve various social problems for "public purposes" (Anheier \& Leat, 2013; Carnegie, 1889). Even though the scope of social problems addressed by institutional philanthropy has evolved over time, philanthropic efforts are largely directed by wealthy donors instead of beneficiary communities (Lynn \& Wisely, 2006; Phillips, S. D. \& Jung, 2016). Consequently, philanthropy is criticized for being undemocratic and unaccountable despite having significant influence on public policy, reluctant to address the economic and political structures that benefit the wealthy, and an inefficient way of disbursing private funds where costs outweigh benefits (Anheier \& Leat, 2013; Karl \& Katz, 1987; Reich, 2018; Roelofs, 2015).

Responding to these concerns, Community Philanthropy (CP) aims to "disrupt and democratise" mainstream philanthropy "by focusing on practices and structures that emphasise people and their assets" (Hodgson, 2020, p. 112). Recognizing that macro global phenomena (e.g., climate change, inequality, conflict, etc.) are experienced at the community-level, CP proposes that community development should be defined, organized, and led by communities that are most impacted by and closest to these issues (Hodgson \& Pond, 2018; Layton, 2016). The European Foundation Centre (2004) defines CP as "the act of individual citizens and local institutions contributing money or goods, along with their time and skills, to promote the wellbeing of local people and the improvement of the community in which they live and/ or work." CP's intersection with community well-being is apparent. Just as community well-being refers to communities acting collectively to improve the "social, economic, environmental, cultural, and political conditions... essential for them to flourish and fulfill their potential" (Wiseman \& Brasher, 2008, p. 358; Phillips, R. \& Pittman, 2009), CP stresses that the utilization of community assets - wealth, knowledge, and social networks - to "build and sustain a strong community" (Layton, 2016; Wilkinson-Maposa, 2017; Doan, 2019, p. 7).

The past decade has seen the "global community philanthropy movement become more visible, vocal, and organised," specially in the arena of international development (Hodgson, 2020, p. 100). Practitioners suggest that CP "symbolize[s] a new approach to development" that centers community assets and ideas (Hodgson \& Knight, 2016) but also takes inspiration from "long-held practices of exchange, mutual aid, solidarity, and community development" (Doan, 2019, p. 3). CP is characterized by the norms and values of "reciprocity, solidarity, social cohesion, selfreliance, and interdependence" (Doan, 2019, p. 5). The Global Fund for Community Foundations (GCFC), an organization that supports CP efforts worldwide, posits that $\mathrm{CP}$ aims to "shift power" into the hands of communities by "building assets, 
strengthening the capacities and agency of communities, and building trust" (Hodgson \& Pond, 2018, p. 11). In this framing, mobilizing local financial resources "from people who understand the context or know the community" is key for "managing, sharing, and devolving power" because by bringing "local money into the equation and co-mingling it with external resources, community philanthropy can introduce a structural (rather than just programmatic) dimension of downward accountability in which ordinary people can become co-owners and stakeholders in their own development processes" (Hodgson, 2020, p. 105). CP is explicit about "building and empowering community leadership" (Layton, 2016, p. 139). Strengthening the capacity and agency of communities also occurs through providing small grants and involving diverse community members in resource allocation decisions (Hodgson, 2020; Kilmurray, 2015). Finally, "trust among different stakeholders (particularly, across power differentials)" is a central concern of CP because "[i]t is valued as an outcome in itself and as something that, when it is present, improves other outcomes as well" (Hodgson, 2020, pp. 110-111).

Funders have pursued CP for values-based and strategic reasons (WilkinsonMaposa, 2017). Values-based funders have sought to cede greater power and agency in the hands of beneficiary communities as an end unto itself. Strategic support for $\mathrm{CP}$ is motivated by the view that when those embedded in a community guide development efforts, it results in "durable" development (Hodgson \& Knight, 2016; Layton, 2016). As such, this is aligned with objectives of the Sustainable Development Goals (SDGs) that, in turn are strongly correlated with the indices for community well-being (e.g., Smale \& Hilbrecht, 2016). These aspirations notwithstanding, gauging the impact of CP on communities remains a challenge (Layton, 2016, p. 140). Some have suggested that CP not only benefits target communities but also is empowering for donors as it fosters cooperative values and behaviours (Doan, 2019, p. 8).

The underlying ideas of $\mathrm{CP}$ are not new; notions of community self-determination, context-specific interventions, and power imbalance between donor and recipients have been captured across different philanthropic approaches, such as, community foundations, grassroots philanthropy, horizontal philanthropy, social justice philanthropy, and others (Harrow et al., 2016; Ruesga, 2011; Suárez, 2012; Wilkinson-Maposa \& Fowler, 2009). Drawing upon principles from across these approaches, CP encapsulates a range of practices and organizational forms that are flexible enough to include a variety of philanthropic efforts (Doan, 2019; Kilmurray, 2015; Knight \& Milner, 2013; Layton, 2016). This very strength of CP also makes is challenging to discern its boundaries; as Doan (2019, p. 3) notes, despite the recent interest in CP, "there is limited guidance for those who wish to apply or invest in community philanthropy approaches." Layton (2016, p. 140) observes that the literature on CP is largely funder or practitioners led with "few strictly scholarly studies of the field," thus leaving outstanding some conceptual issues. He proposes that additional research is needed to understand how "traditional and community forms of philanthropy" can be combined for maximizing the impact of CP (p. 149).

Our intervention comes in this midst, striving to clarify how funders may operationalize the dimensions of power, trust and mutual accountability, and support for self-determination that are core to $\mathrm{CP}$ but are underdeveloped in the extant literature. 
First, when the CP literature refers to shifting power, the goal is to increase downward accountability towards communities and foster greater community agency in matters of project prioritization and funding allocation (Hodgson, 2020; Hodgson \& Pond, 2018). For this, mobilizing local assets is thought to be key. However, the literature gives insufficient attention to how foundations might confront their own positional power over grantees given that power is present in the very structure of philanthropic relationships. A clearer articulation is needed about the work foundations must undertake internally to address questions of power. Second, the CP literature insinuates that trust-building and mutual accountability come through investing in relationships, scaling back reporting requirements, and adapting grantmaking decisions based on community needs (Wilkinson-Maposa, 2017). While these are necessary improvements to the dominant top-down model of philanthropy, it does not account for the fact that merely including community input in grantmaking decisions is not sufficient to produce different resource allocation outcomes or alter the class power donors hold over beneficiary communities (Johnson, J.M., 2016; Silver, 2007). It is contingent upon foundations to use their positional power to create the right kind of "spaces" for meaningful community engagement to tackle systemic issues (Gaventa, 2006). Finally, community self-determination is at the core of CP, yet the practical prescriptions for how foundations can show up in solidarity with communities are sparse. CP needs to outline the role of foundations in challenging entrenched power that benefits the elite (Spade, 2020). Our study uses the case of Thousand Currents to explicate how funders can operationalize the dimensions of confronting power, building trust and mutual accountability, and supporting community self-determination. To examine Thousand Currents' philanthropic model, we develop an analytical model that builds upon CP-related funder practices proposed by Wilkinson-Maposa (2017). In the model, we identify how the dimensions of confronting power and positionality, building trust and mutual accountability, and supporting community self-determination correspond to different CP-related funder practices and how these are operationalized. Table 1 reflects our proposed model.

By applying this model on the case of Thousand Currents, our research tests and refines CP-related funder practices proposed in extant literature. In doing so, our work seeks to offer insights into how interested funders can adopt and operationalize CP.

\section{Note on Methodology}

We use a case-oriented, qualitative research methodology focusing on a single case in order to gain an in-depth understanding of the paradigm of community philanthropy (CP) (Della Porta, 2008; Ragin, 2015). A qualitative case study approach "enables researchers to conduct an in-depth exploration of intricate phenomena" for the purpose of understanding its "multiple facets" in a "naturally occurring context" (Rashid et al., 2019, pp. 1-2). Yin (2009) advises that the case study method is appropriate when answering "how" or "why" questions related to contemporary events. This has direct relevance for our study, which focuses on the case of Thousand Currents to illuminate how the foundation interprets the problems with 


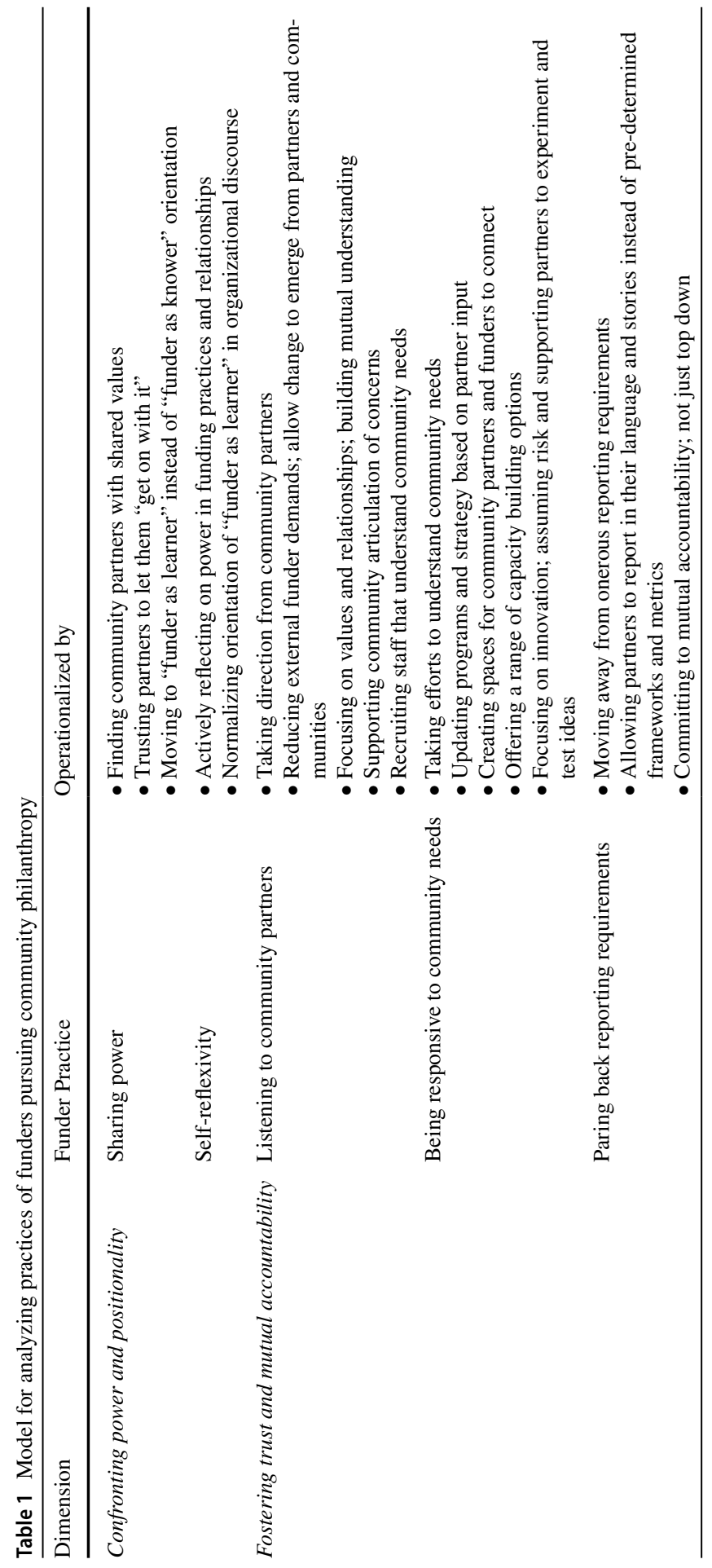




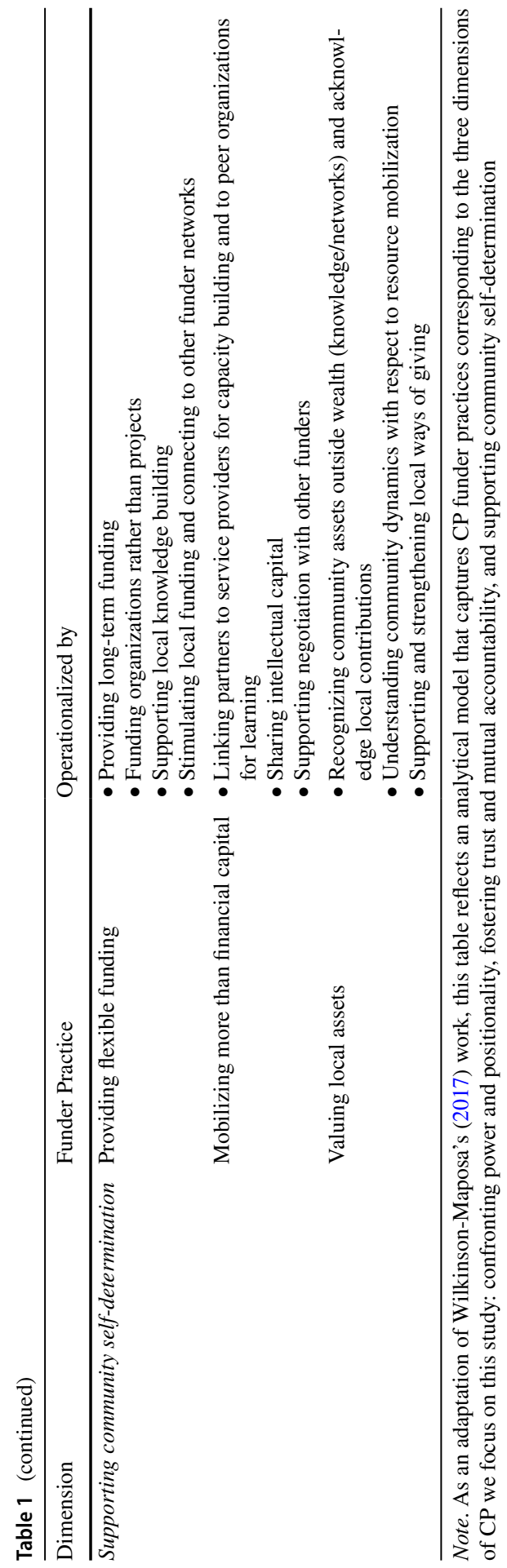


mainstream philanthropy and adopts principles and practices related to $\mathrm{CP}$. Moreover, a case study approach involves "the intensive study of a single unit for the purpose of understanding a larger class of (similar) units" (Gerring, 2004, p. 342). Hence, single case studies can be used for testing and building theory and its inferences can offer insights for understanding other instances of similar phenomenon (Yin, 2009). It follows that Thousand Currents' approach to engaging with the questions of power, mutual accountability, and supporting self-determination (the dimensions of $\mathrm{CP}$ we focus on) can be informative for other funders seeking to apply $\mathrm{CP}$ principles and approaches.

We have selected Thousand Currents as it is a paradigmatic case to make "understandable" the elements of CP (Ragin, 2015). Thousand Currents uses the language of shifting power in its organizational objectives and statements (Thousand Currents, n.d.-a). The organization is a mid-sized public foundation (Frailey, 2017; Squarmilner, 2019) that follows an unorthodox grantmaking model, i.e., it provides unrestricted, long-term grants to grassroots organizations and social movements in the Global South (Thousand Currents, n.d.-a). The foundation also aims to influence the broader philanthropic sector towards adopting trust-based grantmaking. By analyzing the single case of Thousand Currents, we examine the foundation's operations, strategies, and values and their alignment with $\mathrm{CP}$-related funder practices identified in Table 1.

Data for the study are based on reviewing organizational documents and interviewing 10 key informants including grassroots partners (grantees), donors, board members, and members of Thousand Currents staff. The authors' positionality as members of staff and board granted them access to data necessary for the study. To overcome concerns of subjectivity, we relied on bracketing, a "process of setting aside, suspending, or holding in abeyance presuppositions surrounding a specific phenomenon" and "focusing on the essences and structures of the phenomenon" (Gearing, 2004, p. 1432). Prior to conducting interviews with key informants, we made copious notes on our "internal" suppositions (biases and knowledge) and "external" suppositions (how we understood CP ought to operationalized), agreeing to bracket these out mindfully during data collection (Gearing, 2004, pp. 1433-1434). Additionally, to mitigate any bias during interviews, we prepared a theoretically informed interview protocol based on the CP literature review. Following guidance from the qualitative research literature, after each day of interviews, we wrote memos reflecting on any preconceptions that might have affected our engagement with the interview data (Tufford \& Newman, 2012, p. 86). During the data analysis stage, there is a possible tension "between bracketing preconceptions and using them as insight" (Tufford \& Newman, 2012, p. 91). Recognizing this dynamic, we foregrounded informants' views but also "reintegrated" our preconceptions consciously when critically analyzing the interview data (Gearing, 2004).

Table 2 describes the key informants included in our study. The names of informants are anonymized as per the Research Ethics Board approval obtained from Carleton University, Canada. The informants were purposively selected to capture a range of perspectives on Thousand Currents. The three grassroots partners included in the study are from three different regions where Thousand Currents funds initiatives. The representatives at the two donor organizations have 
Table 2 Key informants included in the study

Relationship to Thousand Organization affiliation Date of interview
Currents

Grassroots partners

$\begin{array}{lll}\text { 1. Partner 1 } & \text { Digo Bikas Institute, Kathmandu, Nepal } & \text { Jan 25, 2021 } \\ \text { 2 Partner 2 } & \text { Nepi Behña, Mexico City, Mexico } & \text { Jan 25, 2021 } \\ \text { 3. Partner 3 } & \text { South Durban Community Environmental } & \text { Jan 26, 2021 } \\ & \text { Alliance, Durban, South Africa } & \end{array}$

Donor organizations
4. Donor 1
5. Donor 2
Swift Foundation, NM
Jan 11, 2021
Whitman Institute, CA
Jan 19, 2021
Board Members
6. Board member 1
Kataly Foundation, CA
Jan 19, 2021
7. Board member 2
Hunter College, NY and formerly,
American Jewish World
Service, NY
Jan 29, 2021
Members of Staff

$\begin{array}{lll}\text { 8. Staff } 1 & \text { Thousand Currents, CA } & \text { Dec 4, 2020 } \\ \text { 9. Staff } 2 & \text { Thousand Currents, CA } & \text { Jan 26, 2021 } \\ \text { 10. Staff } 3 & \text { Thousand Currents, CA } & \text { Feb 1, 2021 }\end{array}$

Note. Total number of informants $(n)=10$; Racialized persons $=7$; Global South residents $=4$; Gender: Women $=8$, Men $=2$

had a funding relationship with Thousand Currents for several years. The board members interviewed have been affiliated with Thousand Currents for over five years. The staff members interviewed included the Executive Director and those working in program management. Staff and board perspectives yielded insight into how concerns about mainstream philanthropy were interpreted within Thousand Currents and what organizational choices this motivated. Views of partners and donors allowed us to examine how the actions of Thousand Currents were perceived by external stakeholders.

This research study was approved by the Executive Director and Board Chair of Thousand Currents. Outreach to the key informants was done directly over email, where it was explained that participation in the study was voluntary. We conducted semi-structured interviews with the key informants over Zoom, where we asked about the history of their relationship with Thousand Currents, what they valued about that relationship, and specific questions about how they thought Thousand Currents navigates issues of power, trust, and community solidarity. Informants were enthusiastic and appeared to share their views freely. Except for one interview, which was conducted in Spanish, all interviews were conducted in English. The interviews were transcribed and coded along the themes of power, trust and mutual accountability, and commitment to community self-determination. 


\section{Data Analysis}

In this section, we assess Thousand Currents' philanthropic model underlining how it reflects three different dimensions of CP: confronting power and privilege, building trust and mutual accountability, and exhibiting solidarity towards community self-determination. To this end, we examine different aspects of Thousand Currents' grantmaking practices, such as, the foundation's flexible funding model, how nonfinancial resources are mobilized to benefit grassroots partners, the extent to which input from partners guides the foundation's work, the degree to which Thousand Currents is cognizant of its own positional power, and the steps Thousand Currents takes to recognize partners' knowledge and experience. We begin by introducing Thousand Currents' model of philanthropy, following which we present our findings. Our analysis suggests that Thousand Currents' philanthropic model offers much to animate the practice of $\mathrm{CP}$.

\section{Thousand Currents' Model of Philanthropy}

Without referencing CP directly, Thousand Currents adopts several aspects of CP in its work. Community self-determination, trust, relationship building, mutual accountability, learning, recognition of privilege, and commitment to addressing systemic injustices are core characteristics of Thousand Currents' philanthropic model (Thousand Currents, n.d.-a). These have strong overlaps with the norms of CP such as reciprocity, solidarity, and interdependence (Doan, 2019).

Thousand Currents believes that movement ecosystems - a variety of organizations and movements of different capacities working synergistically - with their grassroots "brilliance" produce social change (Thousand Currents, n.d.-b). In that spirit, Thousand Currents provides unrestricted, long-term grants to movement actors of many types, sizes, and strategies in the regions of Latin America, Africa, and Asia and the Pacific. Grantees include Indigenous Peoples organizations; women, youth, LGBTQ+ led organizations; cooperatives; research and policy think tanks; regional/global coalitions; and others (Thousand Currents, n.d.-c). Thousand Currents is deliberate in referring to its grantees as "partners" indicating a discursive attempt to diminish the inherent power differential in a donor-grantee relationship. Thousand Currents invests in long-term partnerships and co-learning. Thousand Currents also runs the "Thousand Currents Academy," where other institutional funders and wealthy individual donors are invited to engage with and learn about trust and solidarity-based models of grantmaking (Thousand Currents, n.d.-d). The Academy faculty include Thousand Currents' grassroots partners.

Thousand Currents has experienced rapid growth owing to increased recognition of its grantmaking. Thousand Currents' annual budget increased from $\$ 500,000$ in 2010, to \$2 million in 2015, to \$6.7 million in 2019 (Squarmilner, 2019). In 2019, the foundation's funding came from other foundations (80 percent), individuals (17 percent), and earned income through consulting and trainings for other organizations (3 percent) (Thousand Currents, n.d.-e). Thousand Currents neither seeks 
nor receives funds from the U.S. or foreign governments. This secures independence from state led agendas and allows the foundation to partner with innovative groups that fall outside the radar of larger aid agencies restricted by the bureaucratic requirements of government contracts.

\section{Confronting Power and Positionality as a Funder}

Thousand Currents recognizes the existence of unequal power dynamics between funders and grantees. Public remarks by leadership allude to power structures in philanthropy and its evolution through historical processes of colonialism and wealth extraction:

"We have to contend with the fact that the reason that we are making grants in the first place is that there was a process of extraction, which created the wealth that was transferred to us, that we are now transferring to our partners" (Staff 1).

Through organizational discourse and action, Thousand Currents accounts for power in its own relationship with grassroots partners. The foundation frames its work in terms of "redistribution of wealth" (Sahagún, 2016) rather than the traditional language of charity that upholds the positional power of donors. Staff informants pointedly reflected on how the "rhetoric" about their work has evolved to acknowledge funder power:

"There was a time when Thousand Currents used the rhetoric that it was 'partner-led.' Now there is clarity that it's actually 'partner-responsive.' Decisions are still being held by staff, ED and board. Yes, we consult with partners and try to be responsive, but there's a more clear acknowledgement of the power dynamic than saying that this is partner led. Even shifts like that have been really important for the organization to just have a better clarity about how it contends or how it could begin to contend with the kind of inherent power that sits in a funding organization" (Staff 3 ).

The above remarks suggest that the foundation is reflexive about the question of power in its daily work. Thousand Currents is deliberate in choosing discourse that centers the work and views of its grassroots partners. For instance, when describing the crisis of climate change, Thousand Currents does not promote technocratic experts or even itself as the holders of solutions, but rather emphasizes "grassroots solutions" and "grassroots wisdom," which refer to solutions created and held by local communities themselves (Bhansali, 2017; Thousand Currents, 2018c).

In addition, the foundation anchors its work around the values of courage, humility, experimentation, creative collaboration, and interdependence (Swift Foundation, 2020). The foundation maintains an "ever-deepening commitment to continual, reciprocal learning" treating its grassroots partners as "teachers" (Lemma, 2019). Thus, in line with CP-related funder practices, Thousand Currents takes the orientation of "funder as learner" rather than as "knower" (Wilkinson-Maposa, 2017, p. 9). Board informants confirmed this view: 
"Thousand Currents has always been a learning organization that's not trying to say that 'We figured it all out', which is kind of the way that, dare I say, white supremacy and capitalism works. Being a learning organization, it continues to reflect on, 'How are we listening to our grantees? How are we applying those learnings to how we move forward?" (Board member 1).

The board member underlines the importance of learning, reflecting, and "applying those learnings." As a clear example of this, recommendation from partners that Thousand Currents invest in "growing its influence in the field of international philanthropy by becoming a more visible and vocal advocate for its partnership model and building the capacity of other funders to understand how and why it is practiced" propelled the foundation to launch the Thousand Currents Academy (Teng, 2012). The Academy is a week-long immersive training where donors of different stripes - family foundations, impact investors, individual donors, socially conscious businesses, and philanthropic advisors - learn about solidarity as an operating philanthropic principle rooted in political analysis (Thousand Currents, n.d.-d). The Academy uses Indigenous-inspired pedagogy and explores power in donor grantee relationships. For example, participants are asked to reflect on "sovereign logic" - a re-indigenizing practice that seeks to recognize each person's unique way of making sense of their world, which is "shaped by their lineage, the land they come from, and the experiences and learning done through their relationship with others" (Pinto, 2018). These and other relational practices encourage self-reflection and invite attendees to confront power dynamics in interpersonal relationships. This is not merely limited to the realm of the professional but extends to the personal and the political. An attendee, describing his experience at the Academy, said it made him confront questions of race and power and made him realize that philanthropy is "not about charity" but "about recognizing our personal stake in collective liberation" (Delahunt, 2019). Aside from self-reflexive work on relationships to leadership, participants learn directly from the Thousand Currents partners with whom they can discuss how to reframe grantmaking practices. Staff and board informants in this study shared that funder expectations are challenged at the Academy as participants are encouraged to engage in self-reflection, undertake political education, and confront their class privilege. Funders who previously attended the Academy described their experience as "transformative," having impacted their own giving practice. One funder noted of the Academy:

"...just how they are run, the approach, the speakers that are brought in, the attention to meeting people where they are on a personal level, but also on cognitive, theoretical, political level. So, it engages people on a personal level, invites them into the inter-personal with relational and then gives them some frameworks to go forward differently" (Funder 1).

To summarize, Thousand Currents confronts its positional power as a donor by being self-reflexive about organizational discourse and practice. The foundation grounds its work in values of humility and courage. Thousand Currents not only takes a "funder as learner" orientation itself but also runs a program to train other 
funders in grantmaking approaches that question power and privilege and prioritize relationships and trust.

\section{Building trust and mutual accountability}

For Thousand Currents, accountability to its grassroots partners is equally or more important than accountability to its funders. In the words of the Executive Director:

"In traditional philanthropy there is a false sense of security that paperwork, proposals and reports are forms of accountability. We find that this is limiting in the type of relationship we are able to build with our partners. Accountability is about being in the right relationship with our partners. That is a higher bar for how we show up for our partners and how they show up for us." (Staff 1)

With listening and learning as key organizational values, Thousand Currents fosters trust with partners. This involves frequent and responsive communication and honest dialogue. Feedback from grassroots partners have resulted in major changes at Thousand Currents. As noted earlier, partner input prompted the development of the Thousand Currents Academy. Partner critiques forced the foundation to reconsider its previously cumbersome reporting requirements. Accordingly, Thousand Currents has simplified reporting by partners into just one question - what would they like Thousand Currents to know about their work over the grant period in any length or format of their choosing (Lentfer, 2018b). Staff informants shared that the intention of reporting is not monitoring or evaluating partners - language shunned at Thousand Currents - rather, it is to deepen learning about partners' work and context (Staff 2). Thousand Currents achieves this objective by reading partner reports submitted to other funders or reviewing existing partner documents, eliminating the need for partners to prepare special materials for Thousand Currents. Additionally, program staff travel to partner sites in order to cultivate strong interpersonal relationships and develop an understanding of partners' unique contexts. Partners we interviewed appreciated the ease of reporting: "The reporting mechanism is so simple...The reports don't supersede the long-term relationship" (Partner 3). These actions reflect the $\mathrm{CP}$-related funder practices of paring back reporting requirements and listening and being responsive to partner needs (Wilkinson-Maposa, 2017). Staff informants emphasized that accountability toward grassroots partners is practiced in formal and informal ways:

"I think that is a way for us to be accountable, by ensuring that that our grantmaking support is responsive to partners. Then we're always engaged in the relationship to hear what else is needed, what else we can do from our position as a US based philanthropic organization. Accountability is also about being accessible and responsive. We have informal rules like ensuring we respond to partners within a quick time frame, and this also helps us to be accountable" (Staff 2) 
During the 2012 evaluation of the Thousand Currents by its partners - itself an unconventional undertaking - partners indicated they valued the foundation's attitudinal attributes like, "lack of ego and agenda, respect, open communication, responsiveness" (Teng, 2012). Grassroots partner informants in this study also lauded the "attitude" of Thousand Currents:

"The trust with Thousand Currents is based on their attitude. They are very accessible. We discuss and prepare. They don't dictate, it's not domination. They always listen and see and learn from partners. They understand our dynamics" (Partner 3)

This "attitude" of Thousand Currents fosters trust; so much so, that partners feel comfortable giving "negative feedback" without fear of reprisal, such as funding cutbacks: "we feel like we are part of a family, so we see our feedback as a way to course correct our collective approach to the work" (Partner 1). Partners said conversations with other funders revolve around reporting deadlines and deliverables, but Thousand Currents is "interested in what we are doing, they want to hear our stories they want to learn about our context and what difficulties we are facing" (Partner 1). Once again this shows how Thousand Currents, in line with guidance from CP literature, supports community articulation of concerns and focuses on mutual understanding (Wilkinson-Maposa, 2017). Describing engagement on a Thousand Currents initiative involving partners from multiple regions, one partner expressed: “...our opinions are hugely important, and the entire structure is created so that grantees have an equal say as funders...we feel very heard" (Partner 2) [translated from Spanish].

An essential ingredient for such strong mutual trust has to do with values alignment between Thousand Currents and its grassroots partners. WilkinsonMaposa (2017) emphasizes the importance of assessing potential partners against a funders own values. This is in and of itself a relationship building exercise (as opposed to a 'tick box' exercise for grant approval) and is fundamental to trust. Thousand Currents intentionally invests an year getting to know partners under its "catalyst" partnership phase, where alignment of values, vision, and guiding principles is mutually assessed (Thousand Currents, n.d.-f). This encompasses values of interdependence, experimentation, and humility and guiding principles of feminisms, multiplicities, decolonial praxis, and self-determination (Staff 3). Thousand Currents invests in relationship building both before and after partnerships are established. The investment in relationship building prompted a partner to share:

"TC [Thousand Currents] and us, we align in our values. We see each other as allies in this transformational work but from our different positions in the world...This is a relationship of solidarity. It's not a vertical relationship. This has generated our trust in TC. We feel accompanied and supported." (Partner 1)

These comments suggest that the partner perceives there to be alignment between their values and those of Thousand Currents, considering the foundation 
to be an "ally" working together in "solidarity." During interviews, partners underlined that Thousand Currents shares their "vision" for a world where "everyone matters" (Partner 3). These dynamics reflect the practices of CP-related funders who focus on values and relationships (Wilkinson-Maposa, 2017).

In sum, Thousand Currents builds trust and mutual accountability by working with values-aligned grassroots partners and investing in relationship-building and mutual understanding. Partners indicated that Thousand Currents' attitude of humility and openness allowed them to provide frank feedback and view the foundation as an ally. The foundation has a track record of responding to partner feedback by course-correcting its own practices. This creates a virtuous feedback loop, deepening trust with partners.

\section{Showing solidarity for community self-determination}

Thousand Currents expresses it support for the self-determination of its grassroots partners by providing unrestricted core funding, allowing partners to apply that funding toward well-being efforts they decide as important. Thousand Currents also makes a long-term commitment to the vision of its partners and uses its networks to provide support to partners beyond just funding. These actions align with the guidance on CP practice (Hodgson \& Pond, 2018; Wilkinson-Maposa, 2017).

Thousand Currents' grantmaking approach stands apart from the top-down model of traditional philanthropy, where the agenda and parameters for social change are set by the funders. A board member who works in the field of philanthropy clarified that Thousand Currents "challenges" mainstream philanthropy by not pandering to funder "pet passions," but moving resources "in a way that allows communities to identify what their priorities are" (Board member 1). Grassroots partners noted that their relationship with Thousand Currents was special because, unlike other funders, Thousand Currents funding gave them the "freedom" to pursue priorities they saw fit:

"Most donors monitor us based on proposals and reports - they say that if you have done $\mathrm{a}, \mathrm{b}$, c activities mentioned in your proposal then you did ok, and if not, then you failed. But with TC [Thousand Currents], we have the freedom to critically self-reflect and course correct or move to more urgent priorities as needed. We don't have such freedom with other funders as we are tied to proposal commitments." (Partner 1)

Providing unrestricted and flexible funding alongside a learning and listening attitude prompted a partner to indicate that Thousand Currents staff "concern themselves with each and every one of us ensuring that whatever support is needed, its coming through" (Partner 3). Consistently, all partners we interviewed stressed that the flexible funding provided both stability and the ability to adapt to changing contexts. This was especially salient during the COVID-19 pandemic:

"The flexible funding is so important to us. It really helps us to do the things we need to. For instance, after COVID, we had to drastically shift strategies; as women weavers, we realized we needed to have online sales so that the 
women would have some livelihood. We were able to redirect the funding and launch this work immediately without having to think twice." (Partner 2) [translated form Spanish]

Stemming from the belief that social transformation does not happen quickly or linearly and evolves as local contexts change, Thousand Currents makes a long-term commitment to the vision of its grassroots partners even as they change priorities. This view matches observations in CP literature where social change is understood to be "slow and non-linear" (Hodgson, 2020, p. 112). The importance of this approach became most apparent when the pandemic struck in 2020. Partners found themselves providing frontline care to communities, often without government or other support. Thousand Currents recognized that the pandemic placed new burdens on partners, and so, made a commitment to double its grants for the next two years via the "Above and Beyond Solidarity Fund" (Thousand Currents, 2020, 2021a, b). Appreciating Thousand Currents' long-term commitment, a partner remarked:

"Our relationship with Thousand Currents is one of friendship and alliance. We've been partners since 2009. We see them as close allies, not just as funders. This relationship has helped us a lot. We've had some very difficult years, without any funds. But Thousand Currents has stood by us throughout, including now in times of the pandemic, with all the chaos and our inability to do our community work, Thousand Currents showed up with emergency support and doubled grants." (Partner 2) [translated from Spanish]

Additionally, in line with best practices of CP, Thousand Currents provides more than just financial support to its partners (Wilkinson-Maposa, 2017). Among other things, Thousand Currents connects partners to "funders...closest aligned to their work and other donor networks" (Staff 3), supports "learning exchanges" among partners, and raises partner profiles through publicity and award nominations. Partners shared they valued the "moral support" of Thousand Currents along with the "global and regional opportunities for us to share our work" (Partner 1). Speaking of the benefits of learning exchanges, one partner shared:

"Thousand Currents learning exchanges have been key moments of political education for me. I went to Brazil for instance and this was incredible for me to learn about movements from Brazil, Asia, Africa...It's not often that we get such opportunities...I feel like I've really created some deep alliances by being part of that space." (Partner 2) [translated from Spanish]

Thousand Currents actively supports partner campaigns. For example, a Thousand Currents partner, AFEDES - an organization led by Mayan Kaqchikel women - filed a case in Guatemala's highest court to protect intellectual property of Indigenous weaving designs, which were routinely appropriated by corporations for profit without any recognition of the Indigenous culture they came from. Thousand Currents helped to coordinate a media campaign for AFEDES, which amplified the global spotlight on their campaign. The campaign led to an Al Jazeera + video that was watched over 12 million times (Thousand Currents, 2017). 
As the above examples make clear, Thousand Currents supports the self-determination of its grassroots partners by providing long-term financial and other material support. Through this support, partners are able to advance community well-being efforts on their own terms, appropriate to their social and political contexts.

\section{Discussion: Considerations for Operationalizing Community Philanthropy}

In the previous section, we demonstrated how Thousand Current's philanthropic model reflects a practice of $\mathrm{CP}$ through sharing power with grassroots partners, building trust, and supporting community self-determination. In this section, we offer our analysis on how Thousand Currents operationalizes these actions through operational choices.

In allocating private resources for the public benefit, foundations enjoy a great deal of privilege and institutional freedom; yet, funding to community organizations remains very restrictive (Anheier \& Daly, 2006; Toepler, 2018). One of the partners remarked that usually funders impose their own agenda on grassroots organizations citing mandate restrictions or donor stipulations (Partner 1). Thousand Currents overcomes these limitations and advances the flexible funding objectives of $\mathrm{CP}$ by being strategic about its own fundraising. As a public foundation, Thousand Currents seeks support from family foundations and institutional funders willing to provide the type of funding that would, in turn, allow Thousand Currents to provide unrestricted, long-term grants to its grassroots partners (Thousand Currents, n.d.-e). Donor cultivation involves Thousand Currents helping funders recognize the value of Thousand Currents' approach; this provides the foundation the liberty to make investments and take risks that mainstream philanthropic institutions would be unwilling to (Thousand Currents, 2018a). Just as the CP literature advises partnering with values-aligned grantees (Wilkinson-Maposa, 2017), Thousand Currents' philanthropic model points to the importance of seeking values-aligned funders and building funder relationships that are rooted in trust.

Critics have argued that unequal funder-grantee relationships and racial disparities in funding are partly because leadership positions in foundations are occupied by white elites who have limited understanding of the needs of beneficiary communities (Dorsey et al., 2020; Mills, 2016; Villanueva, 2018). Thousand Currents addresses this concern by consciously recruiting staff and board members with links to the Global South communities where Thousand Currents provides funding (Thousand Currents, n.d.-g). A board member was proud that Thousand Currents was among few U.S. philanthropic organizations led by a Black immigrant woman "in the right relationship with social movements" (Board member 1). Since 2009, Thousand Currents has been led by women of color Executive Directors, who have displayed values-driven leadership (Lentfer, 2018a). With regards to hiring, a staff informant asserted: "for us it matters that program staff have come from the region and are people who are engaged in the movement ecosystem" (Staff 3). The board, which supports the vision of the organization and its leadership, comprises of mostly racialized people who either have Global South ties or are connected to social and 
racial justice social movements (Thousand Currents, 2018b, p. 7). Together, there is an understanding that the organization's unorthodox grantmaking approach is a result of the views and values of the people in the organization. As such, these practices follows the guidance from $\mathrm{CP}$ literature to recruit staff that understands community needs (Wilkinson-Maposa, 2017).

Finally, interviews with partners made clear that the strong interpersonal relationships between Thousand Current staff and grassroots partners is essential for trustbuilding, a key element of CP. However, there appears to be an apparent tension between maintaining strong relationships with grassroots partners and growth. Presently, Thousand Currents supports 77 partners, each of whom have a direct relationship with a regional program director. Thousand Currents is still a relatively flat organization with regional program directors maintaining considerable autonomy (though in the last five years, the foundation has added new layers of management). Funders we interviewed praised Thousand Currents for showing "wisdom" about growth and scale; nevertheless, our interviews suggested that the team is actively deliberating over the question of "how can we maintain so many deep relationships with so many groups" while scaling (Staff 3). The staff informant's remarks suggest that the foundation recognizes the importance of "deep relationships" and is grappling with how to maintain this value as the number of partners grow. In the new organizational strategy (still being developed at the time of writing this article), the foundation hopes to address this concern by increasing administrative capacity and program staff.

\section{Conclusion}

In the article, we clarify how foundations can adopt principles and practices of community philanthropy (CP), a philanthropic paradigm that focuses on community self-determination for well-being. By examining the case of Thousand Currents, we demonstrated how a mid-sized public foundation pursues $\mathrm{CP}$ in practice. Thousand Currents 1) confronts its positional power as a funder by choosing discourses that challenge traditional philanthropy, adopting a "funder as learner" orientation, and encouraging peer funders to shift their practices toward solidarity and trust-based grantmaking; 2) builds trust and mutual accountability with values-aligned grassroots partners by investing in strong interpersonal relationships, adopting an attitude of listening and learning, and inviting and acting on critical partner feedback; and 3) supports self-determination of its partners by providing unrestricted, long-term grants and responding to new partner priorities as their social and political contexts evolve. Thousand Currents operationalizes its philanthropic model by working with values-aligned funders and by hiring diverse staff and board who have ties with the regions where Thousand Currents funds partners.

The case of Thousand Currents indicates that the foundation adheres to several CP-related practices outlined in the literature. This includes mobilizing core longterm funding (over project-based grants), lightening reporting burdens, taking direction from community partners, providing non-financial and capacity building support, and connecting partners to different donor networks. The data we collected did 
not directly reveal how Thousand Currents builds and mobilizes financial assets of its community partners - a central aspect of CP (Hodgson, 2020) - although the foundation is pursuing programs for this purpose (see Williams, 2019). The analysis of Thousand Currents' philanthropic model also underlines additional CP-related practices not fully elaborated in the literature. The case suggests that foundations should engage in self-reflection about their positional power and find ways to address it in daily practice. The case also underscores the importance of foundations using their influence to encourage peer organizations and funders in their networks to move towards grantmaking rooted in solidarity instead of charity. The practices of Thousand Currents highlight the importance of cultivating values-aligned relationships with funders (just like with grantees). The case stresses the virtues of humility and learning from the knowledge of grantees. Finally, the Thousand Currents case illustrates the importance of filling decision-making roles in foundations with individuals who have strong connections with and reflect the interests of communities being served.

$\mathrm{CP}$ portends to disrupt mainstream philanthropy by moving from a charity to solidarity model, but often appears as an idealized paradigm. The case study presented in this article demystifies the practice of $\mathrm{CP}$, identifying practical ways in which foundations can adopt $\mathrm{CP}$ and support community well-being.

Acknowledgements We are deeply grateful to the staff and partners of Thousand Currents for their enthusiasm and guidance as we developed this research study. We are also thankful to the anonymous reviewers whose constructive feedback vastly improved the quality of our manuscript.

Funding This study was partially supported by funding from the Pierre Elliott Trudeau Foundation, Canada.

\section{Declarations}

Conflicts of interest/Competing interests Authors are, respectively, a former board member and current staff member of Thousand Currents. This research was not funded by Thousand Currents. There are no other conflicts of interest to declare.

Ethics Approval The ethics protocol for this project was reviewed by the Carleton University Research Ethics Board (Ottawa, Canada) which provided clearance (project \# 114908) to carry out the research. The ethics approval for this project was received on 1 December 2020 and ethics clearance for collection of data expires on 31 December 2021.

Consent to participate and consent for publication Prior to interviews, we obtained consent from key informants participating in the study. They were informed that that data they shared during interviews would remain strictly confidential and used solely for the purposes of this research. The authors had sole possession of the interview data. Informants were told that their answers to open-ended questions may be used verbatim in presentations and publications but we would not identify informants by name, only job title. Informants were told that their organization may be identified in publications.

\section{References}

Anheier, H. K., \& Daly, S. (2006). Philanthropic foundations in modern society. In H. K. Anheier \& S. Daly (Eds.), The politics of foundations: A comparative analysis (pp. 5-26). Routledge. 
Anheier, H. K., \& Leat, D. (2013). Philanthropic foundations: What rationales? Social Research: An International Quarterly, 80(2), 449-472. http://www.jstor.org/stable/24385611

Barman, E. (2008). With strings attached: Nonprofits and the adoption of donor choice. Nonprofit and Voluntary Sector Quarterly, 37(1), 39-56. https://doi.org/10.1177/0899764007303530

Bhansali, R. (2017, May 2). Philanthropy's missed opportunity: Grassroots solutions to climate change. Thousand Currents. Retrieved August 14, 2021, from https://thousandcurrents.org/philanthropysmissed-opportunity-grassroots-solutions-to-climate-change/

Carnegie, A. (1889). Wealth. North American Review, 148(391), 653-664.

Cohen, R. (2014). Data snapshot on racial justice grantmaking. Philanthropic Initiative for Racial Equity. Retrieved August 14, 2021, from https://racialequity.org/wp-content/uploads/2018/11/CIF5DataSnapshot-.pdf

Collins, C., \& Flannery, H. (2020). Gilded giving 2020: How wealth inequality distorts philanthropy and imperils democracy. Institute for Policy Studies. Retrieved August 14, 2021, from https://inequality. org/wp-content/uploads/2020/07/Gilded-Giving-2020-July28-2020.pdf

Delahunt, P. (2019, June 7). Thousand Currents Academy: My Experience. Medium. Retrieved August 14, 2021, from https://medium.com/delapierced/thousand-currents-academy-my-experience-a1b7b c $2 a 569 \mathrm{e}$

Della Porta, D. (2008). Comparative analysis: Case-oriented versus variable-oriented research. In D. Della Porta \& M. Keating (Eds.), Approaches and methodologies in the social sciences: A pluralist perspective (pp. 198-222). Boston: Cambridge University Press.

Doan, D. R. H. (2019). What is community philanthropy? A guide to understanding and applying community philanthropy. Global Fund for Community Foundations. Retrieved August 14, 2021, from https://globalfundcommunityfoundations.org/wp-content/uploads/2019/08/WhatIsCommunityPhila nthropy.pdf

Dorsey, C., Bradach, J., \& Kim, P. (2020). Racial equity and philanthropy: Disparities in funding for leaders of color leave impact on the table. The Bridgespan Group. Retrieved August 14, 2021, from https://www.bridgespan.org/bridgespan/Images/articles/racial-equity-and-philanthropy/racialequity-and-philanthropy.pdf

Eikenberry, A. M. (2006). Philanthropy and governance. Administrative Theory \& Praxis, 28(4), 586592. http://www.jstor.org/stable/25610822

European Foundation Centre. (2004). Community philanthropy watch: Europe 2004. Retrieved August 14, 2021, from https://www.issuelab.org/resource/community-philanthropy-watch-europe-2004. html

Evans, B., Richmond, T., \& Shields, J. (2005). Structuring neoliberal governance: The nonprofit sector, emerging new modes of control and the marketisation of service delivery. Policy and Society, 24(1), 73-97. https://doi.org/10.1016/S1449-4035(05)70050-3

Frailey, K. (2017, January 23). What does the nonprofit sector really look like? Non-profit Insurance Services. Retrieved August 14, 2021, from https://npis.com/what-does-the-nonpr ofit-sector-really-look-like/

Gaventa, J. (2006). Finding the spaces for change: A power analysis. IDS Bulletin, 37(6), 23-33. https:// doi.org/10.1111/j.1759-5436.2006.tb00320.x

Gearing, R. E. (2004). Bracketing in research: A typology. Qualitative Health Research, 14(10), 14291452. https://doi.org/10.1177/1049732304270394

Gerring, J. (2004). What Is a case study and what is it good for? The American Political Science Review, 98(2), 341-354. http://www.jstor.org/stable/4145316

Gilmore, R. W. (2016). In the shadow of the shadow state. S\&F Online, 13(2), 1-7.

Giloth, R. (2019). Philanthropy and economic development: New roles and strategies. Economic Development Quarterly, 33(3), 159-169. https://doi.org/10.1177/0891242419839464

Harrow, J., \& Jung, T. (2016). Philanthropy and community development: The vital signs of community foundation? Community Development Journal, 51(1), 132-152. https://doi.org/10.1093/cdj/bsv056

Harrow, J., Jung, T., \& Phillips, S. D. (2016). Community foundations: Agility in the duality of foundation and community. In T. Jung, S. D. Phillips, \& J. Harrow (Eds.), The Routledge companion to philanthropy (pp. 308-321). Routledge.

Hodgson, J. (2020). Disrupting and democratising development: Community philanthropy as theory and practice. Gender \& Development, 28(1), 99-116. https://doi.org/10.1080/13552074.2020.1717214

Hodgson, J., \& Knight, B. (2016, November 26). \#ShiftThePower: The rise of community philanthropy. Alliance Magazine. Retrieved August 14, 2021, from https://www.alliancemagazine.org/feature/ shiftthepower-rise-community-philanthropy/ 
Hodgson, J., \& Pond, A. (2018). How community philanthropy shifts power. Grantcraft. Retrieved August 14, 2021, from https://grantcraft.org/content/guides/how-community-philanthropy-shifts-power

Hossein, C. S. (2020, March 24). Mutual aid and physical distancing are not new for Black and racialized minorities in the Americas. HistPhil. Retrieved August 14, 2021, from https://histphil.org/2020/ 03/24/mutual-aid-and-physical-distancing-are-not-new-for-black-and-racialized-minorities-in-theamericas/

Johnson, J. M. (2016). Necessary but not sufficient: The impact of community input on grantee selection. Administration \& Society, 48(1), 73-103. https://doi.org/10.1177/0095399713509241

Johnson, P. D. (2018). Global philanthropy report: Perspectives on the global foundation sector. The Hauser Institute for Civil Society, Harvard Kennedy School. Retrieved August 14, 2021, from https://cpl.hks.harvard.edu/files/cpl/files/global_philanthropy_report_final_april_2018.pdf

Karl, B. D., \& Katz, S. N. (1987). Foundations and ruling class elites. Daedalus, 116(1), 1-40. http:// www.jstor.org/stable/20025085

Kilmurray, A. (2015). Participatory decision-making in contested societies: Examples from the field of community philanthropy. The Foundation Review, 7(3). https://doi.org/10.9707/1944-5660.1256

Knight, B., \& Milner, A. (2013). What does community philanthropy look like? C.S. Mott Foundation. Retrieved August 14, 2021, from https://www.mott.org/wp-content/uploads/2016/05/WhatDoesCo mmunityPhilanthropyLookLike.pdf

Kohl-Arenas, E. (2015). The self-help myth: Towards a theory of philanthropy as consensus broker. American Journal of Economics and Sociology, 74(4), 796-825. https://doi.org/10.1111/ajes.12114

Layton, M. D. (2016). Philanthropy at the community level: Supporting community empowerment. In T. Jung, S. D. Phillips, \& J. Harrow (Eds.), The Routledge companion to philanthropy (pp. 139-150). Routledge.

Lee, S. J., Kim, Y., \& Phillips, R. (2015). Exploring the intersection of community well-being and community development. In S. J. Lee, Y. Kim, \& R. Phillips (Eds.), Community well-being and community development: Conceptions and applications (pp. 1-7). Springer. https://doi.org/10.1007/ 978-3-319-12421-6_1

Lemma, S. (2019, March 2). Moving with movements. Thousand Currents. Retrieved August 14, 2021, from https://thousandcurrents.org/moving-with-movements/.

Lentfer, J. (2018a, October 15). Leaving on a high note: 9 ways to align your leadership transition with your values. Thousand Currents. Retrieved August 14, 2021, from https://thousandcurrents.org/leavi ng-on-a-high-note-9-ways-to-align-your-leadership-transition-with-your-values/

Lentfer, J. (2018b, December 13). What if foundations instead asked just ONE question for grant reporting? Thousand Currents. Retrieved August 14, 2021, from https://thousandcurrents.org/what-iffoundations-asked-just-one-question-for-grant-reporting/

Lynn, E., \& Wisely, S. (2006). Four traditions of philanthropy. In A. Davis \& E. Lynn (Eds.), The civically engaged reader (pp. 210-217). Great Books Foundation.

Mills, F. (2016). The state of change. Council on Foundations. Retrieved August 14, 2021, from https:// www.cof.org/sites/default/files/documents/files/2017-Gender-Diversity-Report.pdf

OECD. (2019). OECD statistics on private philanthropy for development: Highlights from the latest data on 2018-19. Organisation of Economic Co-operation and Development. Retrieved August 14, 2021, from https://www.oecd.org/dac/Private-Philanthropy-for-Development-Flyer-2018-19.pdf

Ostrander, S. A. (2007). The growth of donor control: Revisiting the social relations of philanthropy. Nonprofit and Voluntary Sector Quarterly, 36(2), 356-372. https://doi.org/10.1177/0899764007 300386

Phillips, R., \& Pittman, R. H. (2009). A framework for community and economic development. In R. Phillips \& R. H. Pittman (Eds.), An introduction to community development (pp. 3-19). Routledge.

Phillips, S. D., \& Jung, T. (2016). Introduction - A new 'new' philanthropy: From impetus to impact. In T. Jung, S. D. Phillips, \& J. Harrow (Eds.), The Routledge companion to philanthropy (pp. 5-34). Routledge.

Pinto, S. (2018). The power of story and witness. William C. Friday Fellowship for Human Relations. Retrieved August 14, 2021, from https://cdn.ymaws.com/www.fridayfellowship.org/resource/ resmgr/images/SayraPintoPost1-Circling.pdf

Ragin, C. C. (2015). Case-oriented research. In J. D. Wright (Ed.), International encyclopedia of the social and behavioral sciences (pp. 187-193). Elsevier.

Rashid, Y., Rashid, A., Warraich, M. A., Sabir, S. S., \& Waseem, A. (2019). Case study method: A stepby-step guide for business researchers. International Journal of Qualitative Methods, 18. https://doi. org/10.1177/1609406919862424 
Reich, R. (2018). Just giving: Why philanthropy is failing democracy and how it can do better. Princeton University Press.

Roelofs, J. (2015). How foundations exercise power. American Journal of Economics and Sociology, 74(4), 654-675. https://doi.org/10.1111/ajes.12112

Ruesga, G. A. (2011). Civil society and grassroots philanthropy. In The Oxford handbook of civil society (pp. 455-467). Oxford University Press. https://doi.org/10.1093/oxfordhb/9780195398571.013. 0036

Sahagún, A. (2016, December 30). Buen Vivir Fund interested investors webinar. Regenerative Finance. Retrieved August 14, 2021, from http://regenerativefinance.com/blog/

Schlegel, R. (2016). Pennies for progress: A decade of boom for philanthropy, a bust for social justice. National Committee for Responsive Philanthropy. Retrieved August 14, 2021, from https://www. ncrp.org/publication/pennies-for-progress

Silver, I. (2007). Disentangling class from philanthropy: The double-edged sword of alternative giving. Critical Sociology, 33(3), 537-549. https://doi.org/10.1163/156916307X189013

Smale, B., \& Hilbrecht, M. (2016). Mapping the Canadian index of wellbeing to the United Nations Sustainable Development Goals. University of Waterloo. Retrieved August 14, 2021, from https://uwate rloo.ca/canadian-index-wellbeing/sites/ca.canadian-index-wellbeing/files/uploads/files/ciw-mappi ng_the_ciw_to_un_sdgs-oct2016-final.pdf

Spade, D. (2020). Solidarity not charity: Mutual aid for mobilization and survival. Social Text, 38, no. 1, (142), 131-151. https://doi.org/10.1215/01642472-7971139

Squarmilner. (2019). Thousand Currents and subsidiary consolidated financial statements. Thousand Currents. Retrieved August 14, 2021, from https://thousandcurrents.org/wp-content/uploads/2020/ 12/Thousand-Currents-FY19-Audit.pdf

Suárez, D. F. (2012). Grant making as advocacy: The emergence of social justice philanthropy. Nonprofit Management and Leadership, 22(3), 259-280. https://doi.org/10.1002/nml.20054

Swift Foundation. (2020, April 29). Reflections: Solidarity philanthropy webinar in the face of the COVID-19 crisis and beyond. Retrieved August 14, 2021, from https://swiftfoundation.org/refle ctions-solidarity-philanthropy-in-the-face-of-the-covid-19-crisis-and-beyond/

Teng, S. (2012). 2012 IDEX evaluation and learning report (summary). Thousand Currents. Retrieved August 14, 2021, from https://thousandcurrents.org/wp-content/uploads/2017/03/2012-Evaluationand-Learning-Summary.pdf

Thousand Currents. (2017, August 7). Weaving a narrative. Retrieved August 14, 2021, from https:// thousandcurrents.org/weaving-a-narrative/

Thousand Currents. (2018a). Rising Currents 2018-2021. Retrieved August 14, 2021, from https://thous andcurrents.org/wp-content/uploads/2018/04/Strategy.pdf

Thousand Currents. (2018b). Return of organization exempt from income tax [Form 990]. Retrieved August 14, 2021, from https://thousandcurrents.org/wp-content/uploads/2020/12/Thousand-Curre nts-FY19-990.pdf

Thousand Currents. (2018c, January 8). What if we saw "mistakes" as fuel for innovation? Retrieved August 14, 2021, from https://thousandcurrents.org/mistakes-fuel-innovation-smart-risks/

Thousand Currents. (2020, March 24). Above \& Beyond Solidarity Fund: Supporting grassroots action against COVID-19. Retrieved August 14, 2021, from https://thousandcurrents.org/above-beyondsolidarity-fund/

Thousand Currents. (2021, March 8). The next chapter of our Above \& Beyond Solidarity. Retrieved August 14, 2021, from https://thousandcurrents.org/the-next-chapter-of-our-above-and-beyond-solid arity/

Thousand Currents. (n.d.-a). Frequently asked questions. Retrieved August 14, 2021, from https://thous andcurrents.org/faqs/

Thousand Currents. (n.d.-b). Vision, values, and theory of change. Retrieved August 14, 2021, from https://thousandcurrents.org/about/

Thousand Currents. (n.d.-c). Our partnership model. Retrieved August 14, 2021, from https://thousandcu rrents.org/our-model/

Thousand Currents. (n.d.-d). About the academy. Retrieved August 14, 2021, from https://academy.thous andcurrents.org/about

Thousand Currents. (n.d.-e). Our financials. Retrieved August 14, 2021, from http://thousandcurrents. org/financials/

Thousand Currents. (n.d.-f). Our partners. Retrieved August 14, 2021, from http://thousandcurrents.org/ partners/ 
Thousand Currents. (n.d.-g). Staff. Retrieved August 14, 2021, from https://thousandcurrents.org/staff/

Toepler, S. (2018). Public philanthropic partnerships: The changing nature of government/foundation relationships in the US. International Journal of Public Administration, 41(8), 657-669. https://doi. org/10.1080/01900692.2017.1295462

Tufford, L., \& Newman, P. (2012). Bracketing in qualitative research. Qualitative Social Work, 11(1), 80-96. https://doi.org/10.1177/1473325010368316

Villanueva, E. (2018). Decolonizing wealth: Indigenous wisdom to heal divides and restore balance. Berrett-Koehler Publishers.

Wilkinson-Maposa, S. (2017). A different kind of funder? Why and how funders support community philanthropy. Global Fund for Community Foundations. Retrieved August 14, 2021, from https://globa lfundcommunityfoundations.org/wp-content/uploads/2019/04/DifferentKindOfFunder_WilkinsonM aposa.pdf

Wilkinson-Maposa, S., \& Fowler, A. (2009). The poor philanthropist II: New approaches to sustainable development. Green Point, South Africa: Southern Africa-United States Centre for Leadership and Public Values. Retrieved August 14, 2021, from https://www.issuelab.org/resources/13933/13933. pdf

Williams, E. (2019, November 15). The Buen Vivir Fund for impact investment. BORGEN. Retrieved August 14, 2021, from https://www.borgenmagazine.com/the-buen-vivir-fund-for-impact-inves tment/

Wiseman, J., \& Brasher, K. (2008). Community wellbeing in an unwell world: Trends, challenges, and possibilities. Journal of Public Health Policy, 29(3), 353-366. https://doi.org/10.1057/jphp.2008.16

Yin, R. K. (2009). Case study research: Design and methods. SAGE.

Publisher's Note Springer Nature remains neutral with regard to jurisdictional claims in published maps and institutional affiliations. 